\title{
Starch Granule and Protein Accumulation during Seed Development of Ginkgo biloba $L$.
}

\author{
Biao Jin,, ${ }^{1}$ Yan Xie, ${ }^{1}$ Yan Lu, ${ }^{1}$ Di Wang, ${ }^{2}$ Min Zhang, ${ }^{1}$ and Li Wang1 \\ ${ }^{1}$ College of Horticulture and Plant Protection, Yangzhou University, Yangzhou 225009, China \\ ${ }^{2}$ College of Biological Sciences and Biotechnology, Yangzhou University, Yangzhou 225009, China
}

Correspondence should be addressed to Li Wang, liwang@yzu.edu.cn

Received 21 September 2012; Accepted 24 October 2012

Academic Editors: M. Adrian, J. F. Gutierrez-Marcos, and S. Satoh

Copyright ( 2012 Biao Jin et al. This is an open access article distributed under the Creative Commons Attribution License, which permits unrestricted use, distribution, and reproduction in any medium, provided the original work is properly cited.

\begin{abstract}
We investigated starch and protein formation and accumulation in the seed of Ginkgo biloba L. In the testa, starch granules and protein bodies (PBs) started to form and accumulate 30 days after pollination; they decreased in size and completely disappeared before maturity. In the endosperm, starch granules began to accumulate 45 days after pollination, and the number and size of starch granules increased gradually within 65 days after pollination. Starch granules, which were mainly produced in plastids, proliferated mainly by constricting in the center and dividing to form smaller granules. Before harvest, there were ellipsoidal or irregularly shaped types, including A-type starch granules and some B- and C-type starch granules. In addition, PBI and PBII formed mainly in the outermost cells of the endosperm. However, the starch granules and protein bodies in endosperm cells around the embryo disappeared completely. The embryo cells contained many organelles, C-type starch granules, and PBI-type protein bodies. These results suggested that the starch granules were A-, B-, and C-types, and the protein bodies were PBI- and PBII-types in G. biloba. In addition, there were many significant differences in the formation, accumulation, and types of starch granules and protein bodies among the testa, endosperm, and embryo.
\end{abstract}

\section{Introduction}

Ginkgo biloba L., one of the most primitive extant gymnosperms, is the only living species of the ancient lineage of Ginkgophyta [1]. It is used as a medicinal plant and is one of the most important economic tree species exclusively occurring in China. Recent studies showed that G. biloba seeds consist of the testa, the endosperm, and the embryo. The testa covers the seed and protects the endosperm [2]; the endosperm is the main edible part of the seed that contains nutrients, starch, and proteins [3, 4]; and the embryo ripens in December after gathering because of its after-ripening trait. There have been some studies on starch and protein accumulation during the development of Ginkgo seeds, and most studies have focused on the endosperm. FavreDuchartre (1958) [5] observed the starch granules in the prothallus of G. biloba and showed that the starch granules had an irregularly shape with a central hilum. Generally, the starch granules were classified into two types based on their size: $4-5 \mu \mathrm{m}$ and $15-20 \mu \mathrm{m}$ in G. biloba. In addition, previous studies showed that the formation time and filling pattern of starch granules differed among different locations in the endosperm [3]. However, few about the formation process of nutrients in the different tissues was studied which is very important for a comprehensive understanding of seed development in G. biloba. As well, the accumulation of major nutrients such as starch and protein in seed tissues during the seed development process determines the nutritional quality of Ginkgo seeds.

In this study, on the basis of our previous studies on development of the female gametophyte and embryo in G. biloba [6-9], we collected Ginkgo seeds at different stages of growth and then observed the formation and accumulation of starch granules and protein bodies in the testa, endosperm, and embryo during the developmental process. These results further our knowledge of seed development in Ginkgo, one of the most primitive seed plants.

\section{Materials and Methods}

2.1. Experimental Materials. The experimental materials were ovules and seeds from female Ginkgo trees (approx. 


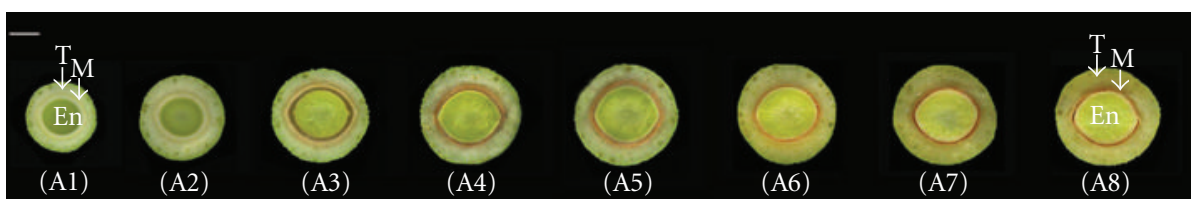

(a)

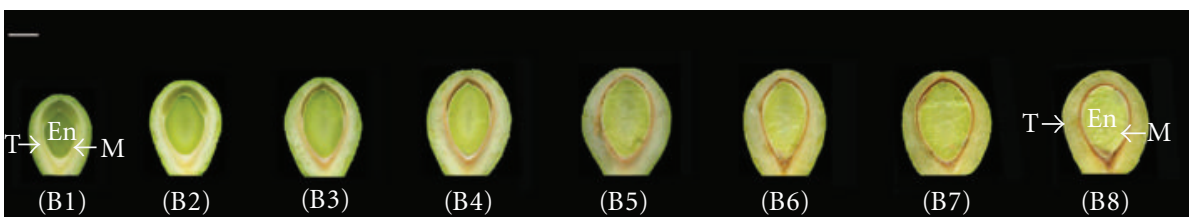

(b)

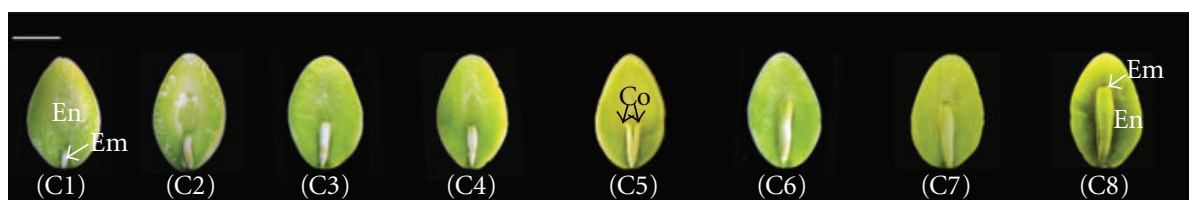

(c)

Figure 1: Seed development in G. biloba. (a) Development of testa; (b) development of endosperm; (c) development of embryo; ((A1), (B1)) 50 days after pollination; ((A2), (B2)) 65 days after pollination; ((A3), (B3)) 80 days after pollination; ((A4), (B4)) 95 days after pollination; ((A5), (B5)) 110 days after pollination; ((A6), (B6)) 125 days after pollination; ((A7), (B7)) 140 days after pollination; ((A8), (B8)) 155 days after pollination; (C1) 10 days after harvest; (C2) 15 days after harvest; (C3) 20 days after harvest; (C4) 25 days after harvest; (C5) 30 days after harvest; (C6) 40 days after harvest; (C7) 50 days after harvest; (C8) 60 days after harvest; T: testa; M: mesocoat; En: endosperm; Em: embryo; Co: cotyledon. Bar $=1 \mathrm{~cm}$.

20 years old) growing at the Ginkgo Experimental Station, Yangzhou University, Yangzhou, China ( $\left.32^{\circ} 20^{\prime} \mathrm{N}, 119^{\circ} 30^{\prime} \mathrm{E}\right)$. The samples were collected as follows. (1) From mid-April to mid-September (from the pollination of the ovules to the ripening of the seeds), we collected 30 seeds every 5 days. The testa and endosperm were excised from the samples under a stereomicroscope and cut into $1 \times 1 \mathrm{~cm}$ samples. (2) Seeds were collected after they reached maturity, and the testa was wiped clean. The mature seeds were stored in wet sand, and 30 seeds were removed each week for analysis. The endosperm was removed by razor from the seeds, and the embryos were used as the experimental sample. All samples were fixed in $2.5 \%$ glutaraldehyde and stored at $4^{\circ} \mathrm{C}$ until analysis.

2.2. Observation under Stereomicroscope. Ginkgo seeds collected in different periods were cut longitudinally and transversely and then observed and photographed under a stereomicroscope.

2.3. Semithin Sectioning and Transmission Electron Microscopy (TEM). The samples described in Section 2.1 were fixed with $1 \%$ osmic acid, dehydrated in an ethanol gradient series, immersed in epoxypropane and then embedded in Spurr's resin. The samples were cut into $1-\mu \mathrm{m}$ semithin sections and stained with $1 \%$ toluidine blue (TBO) before being observed and photographed under a microscope (Zeiss Axioskop 40: Carl Zeiss Shanghai Company Ltd., Shanghai, China). For ultrastructural observations, ultrathin sections ( $50 \mathrm{~nm}$ ) were cut with a microtome and then double-stained with $6 \%$ uranyl acetate and Satoh's lead mixture before being observed and photographed under a Tecnai 12-TWIN transmission electron microscope.

2.4. Statistics and Analysis. We selected 30 Ginkgo seeds from each period and determined the length and shape of the embryo. Values for length and shape were summed to calculate percentage values. We selected 30 testa cells and endosperm cells in the semithin sections then determined the number of starch granules in each cell at each period and the amounts of different types of starch granules. These values were used to calculate the percentage of each type of starch granules.

\section{Results}

3.1. Seed Development Process in G. biloba. In areas around Yangzhou, China, pollination of G. biloba begins in early April. By 50 days after pollination, all tissues in the seed had differentiated, including the testa, mesosperm, and endosperm. The cells of the mesocoat were tightly compacted (Figure 1 (A1), (B1)). By 65 days after pollination, the volume of endosperm continued to increase, and the mesocoat hardened (Figure 1 (A2), (B2)). By 80 days after pollination, the testa and endosperm reached their maximum volumes, and the mesocoat gradually cemented (Figure 1 (A3), (B3)). Thereafter, the volume of the seed did not change significantly, and the seed became elliptical in shape with vertical axis of $3.1 \mathrm{~cm}$ and an equatorial axis of $2.4 \mathrm{~cm}$ (Figure 1 (A4), (A5), (A6), (A7), (B4), (B5), (B6), (B7)). By 155 days after pollination, the seeds had ripened, the testa had changed 
from white to golden, and the endosperm had changed from green to chartreuse (Figure 1 (A8), (B8)).

The Ginkgo seeds were collected in mid-September, and due to the late fertilization and a significant non-synchronization, the embryos were round and small. Ginkgo seeds show an after-ripening characteristic, which means that the seed continues to grow after harvest. By 10 days after collection, the volume of the embryos had increased, and approximately $90 \%$ were cylindrical while the other $10 \%$ were globular. The embryos formed at the micropylar end of the endosperm beads (Figure $1(\mathrm{C} 1)$ ). As the embryo continued to grow, the cotyledons gradually differentiated and grew upwards (Figure 1 (C2), (C3), (C4), (C5), (C6), (C7)) until the end of December. At this time, the embryo was fully developed with a length of $1.2 \mathrm{~cm}$. The endosperm cells around the embryo appeared significantly depressed (Figure 1 (C8)). In addition, among the samples observed, embryo abortion occurred in approximately $30 \%$ of the seeds.

3.2. Formation and Accumulation of Protein Bodies and Starch Granules in the Testa. In Ginkgo seeds, the testa is differentiated from the outer part of the integument. At 20 days after pollination, many parenchyma cells had differentiated in the testa, and there were few starch granules present. However, some idioblasts with dense cytoplasm were present in the testa. Using a double-staining technique, the idioblasts were colored red by periodic acid-schiff staining (supplementary Figures A and B available online at doi:10.5402/2012/653796), indicating that they contained amylose; toluidine blue $\mathrm{O}$ staining, which stains proteins blue, showed that they also contained abundant proteins (Figure 2(a)). By 30 days after pollination, the layers of parenchyma cells in testa increased, and some starch granules had begun to accumulate in the cells (Figure 2(b)). Most of the starch granules were small and spherical, with a diameter of $2-6 \mu \mathrm{m}$. On average, there were approximately 25 starch granules per cell. There were some protein bodies among the starch granules (Figures 2(c) and 2(d)). As the volume of idioblasts increased, the cytoplasmic area stained more deeply. At this time, more idioblasts were distributed near the epidermis and accumulated to their highest level (Figure 2(b)). By 60 days after pollination, the testa was covered by a thick, waxy layer, and there were 6 to 8 layers of prolate cells with thickened cell walls (Figure 2(e)). The volume of parenchyma cells increased, and the starch granules were located near the cell walls. The number of starch granules decreased gradually, reaching an average of 18 starch granules per cell (Figure 2(f)). At this time, idioblasts began to disaggregate (Figure 2(e)). By 130 days after pollination, some starch granules were still present in the parenchyma cells of the testa, but there were fewer starch granules, and no protein bodies. The idioblasts gradually disintegrated, and the cytoplasm stained more lightly (Figures 2(g) and 2(h)). When the seeds of G. biloba reached maturity, starch granules and protein bodies in testa had completely disappeared and the cytoplasm of idioblasts was breaking down (Figures 2(i) and 2(j)).
By 20 days after pollination, the testa cells contained organelles such as mitochondria and chloroplasts (Figure 3(a)). The chloroplasts were ellipsoidal and contained an embedded starch granule. However, abundant lipid droplets and some starch granules were also observed in chloroplasts with swollen thylakoids, indicating chloroplast degeneration (Figures 3(b) and 3(c)). At 25 days after pollination, many plastids in the testa had accumulated starch granules, which were forming amyloids. The C-type starch granules were spherical with a diameter of 2-3 $\mu \mathrm{m}$ early in their development. These starch granules were often surrounded by a mesh network of the endoplasmic reticulum (ER) (Figure 3(d), arrows), suggesting that the synthesis of small starch granules was associated with the endoplasmic reticulum. At this time the protein bodies were different in size but all were round. The type I protein bodies (PBI) stained deeply, and the endoplasmic reticulum was distributed around them (Figure 3(e)). By 30 days after pollination, the volume of plastids had increased while the mesh network surrounding them had disappeared. The starch granules had formed into ellipsoidal-shaped B-type and Ctype granules with a diameter of $2-8 \mu \mathrm{m}$ (Figure $3(\mathrm{f})$ ).

\subsection{Formation of Different Types of Starch Granules and Accu-} mulation of Protein Bodies in Endosperm. The endosperm tissue of Ginkgo seed is directly derived from the megaspore mother cell. By 50 days after pollination, the endosperm tissue consisted of parenchyma cells, which had begun to accumulate starch granules. The starch granules that formed early in this process were spherical or ellipsoidal, small and located close to the cell wall (Figure 4(a)). In addition, the number and volume of starch granules increased during this period. Thus, by 65 days after pollination, there was an average of 30 starch granules per parenchyma cell. The starch granules were irregularly shaped with a diameter ranging from 3 to $25 \mu \mathrm{m}$. Three types of starch granules were present: approximately $10 \%$ were C-type (diameter < $5 \mu \mathrm{m}$ ); approximately $85 \%$ were B-type (diameter $5-10 \mu \mathrm{m}$ ); and approximately $5 \%$ were A-type (diameter $>10 \mu \mathrm{m}$ ) (Figure 4(b)). By 80 days after pollination, the endosperm tissues had formed two separate parts: an outer layer of small, closely arranged cells and inner layers of parenchyma cells. Starch granules accumulated mainly in the cells in the inner layers, and the number of starch granules did not increase further after this point, but their volume increased, resulting in approximately $70 \%$ A-type starch granules. At this time, the starch granules were still irregular in shape, and most were located close together. Small protein bodies also appeared at this time and were distributed among the starch granules (Figure 4(c)). Large, spherical protein bodies or small granule-shaped protein bodies accumulated mainly in the outer layer, and some starch granules accumulated also (Figure 4(d)). By 110 days after pollination, the volume of starch granules in endosperm inner cells had increased, and the starch granules were elliptical or spherical, with a few showing an irregular shape (Figure 4(e)). At this time, the accumulation of protein bodies in the cells of outer layers increased and reached its maximum (Figure 4(f)). Afterwards, both the amount and volume of starch granules 


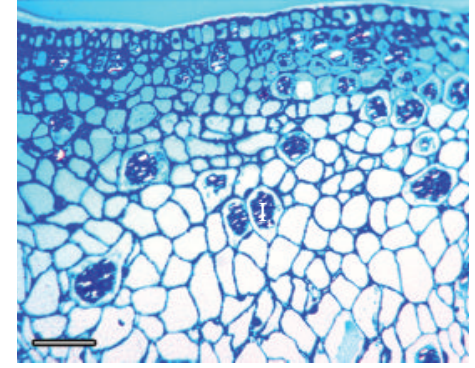

(a)

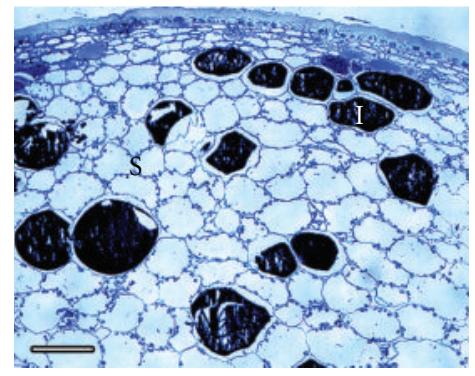

(e)

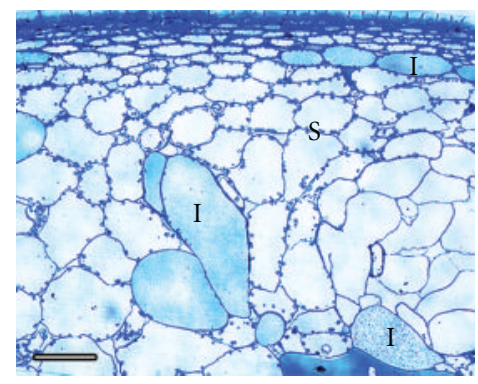

(h)

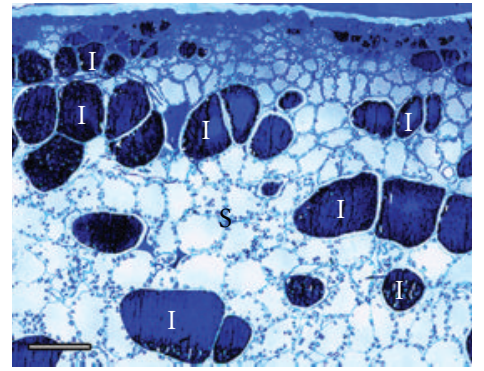

(b)

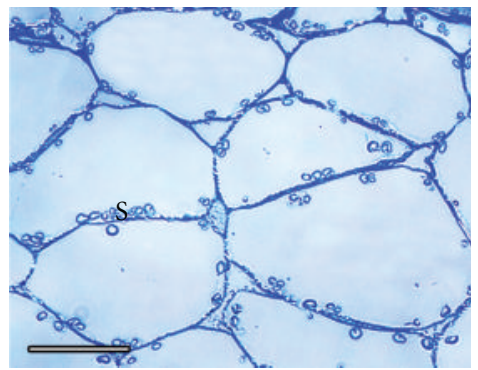

(f)

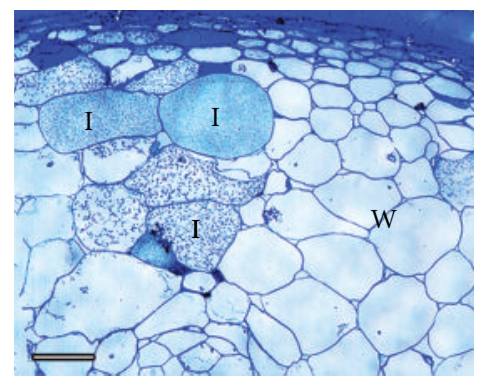

(i)

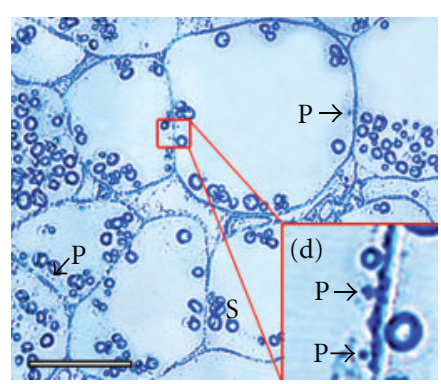

(c)

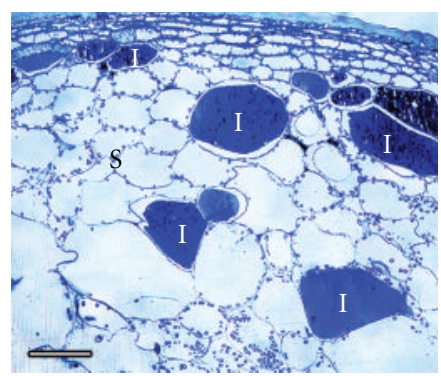

(g)

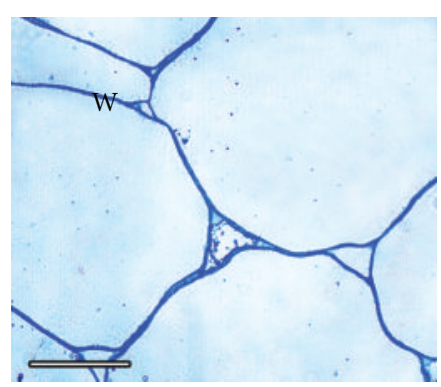

(j)

FIgURE 2: Starch and protein accumulation during testa development in G. biloba seeds. (a) 20 days after pollination; ((b), (c)) starch granules accumulated in testa cells 30 days after pollination; (d) protein accumulated in testa cells 30 days after pollination; ((e), (f)) 60 days after pollination; (g) 110 days after pollination; (h) 130 days after pollination; ((i), (j)) starch granules disappeared by 150 days after pollination. Figure (j) shows an amplified region from Figure (i); I: idioblast; P: protein body; S: starch granule; W: wall. Bar $=50 \mu \mathrm{m}$.

did not increase further. When the seeds reached maturity, most starch granules (80\%) were A-type, and were mainly accumulated in endosperm inner cells. Some B-type and C-type starch granules were present as well (Figure 4(g)). However, the protein bodies mainly accumulated in the endosperm outer layers cells (Figure $4(\mathrm{~h})$ ) and were distributed among the starch granules (Figure $4(\mathrm{~g})$ ). In particular, the endosperm cells around the embryo began to degrade, their cell walls shrunk and deformed, and nutrients such as protein bodies and starch granules almost completely disappeared, leaving only a few starch granules close to the cell walls (Figure 4(i)).

Ultrastructural observations of starch granules and protein bodies in the endosperm showed that a few starch granules accumulated in chloroplasts, but the chloroplast grana lamellae became expansive by 50 days after pollination (Figure 5(a)). Some starch granules also accumulated in the plastids (Figure 5(b)). By 80 days after pollination, the shape of starch granules had become irregular and stretched along the vertical axis to reach a length of $10 \mu \mathrm{m}$. In the stretched starch granules constricted in the middle regions and split into small starch granules of different sizes (Figure 5(c)). By 110 days after pollination, there were mature A-type, Btype, and C-type starch granules. The starch granules with a regular, round shape often had a hilum in the center and a double layer membrane (Figures 5(d) and 5(e)). There were two types of protein bodies: PBI, which were larger and spherical and PBII, which stained more deeply and accumulated in the vacuole (Figure 5(f)). By 130 days after pollination, the nucleolus in the endosperm cells had begun to degenerate (Figure $5(\mathrm{~g})$ ). When the seeds reached maturity and fell from the tree, there were some C-type starch granules distributed away from the location where the embryo formed in the endosperm cells (Figure 5(h)) and there were abundant spherical protein bodies with a diameter of less than $1 \mu \mathrm{m}$ (Figure 5(i)).

\subsection{Formation and Accumulation of Starch Granules and} Protein Bodies in Embryo. From 10 to 50 days after seed harvest, the embryo in the seed was still developing and 


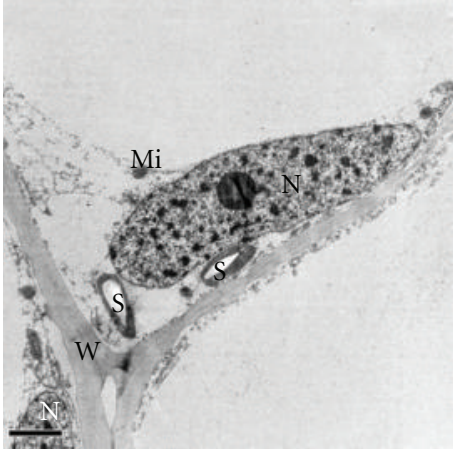

(a)

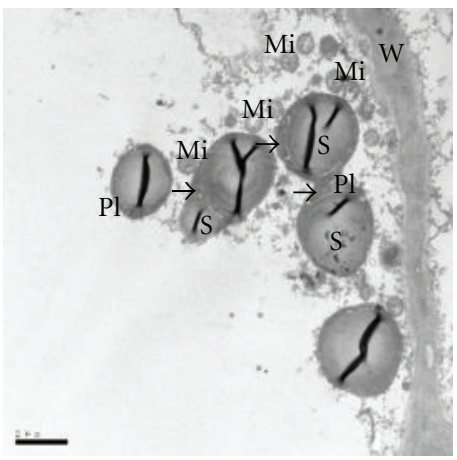

(d)

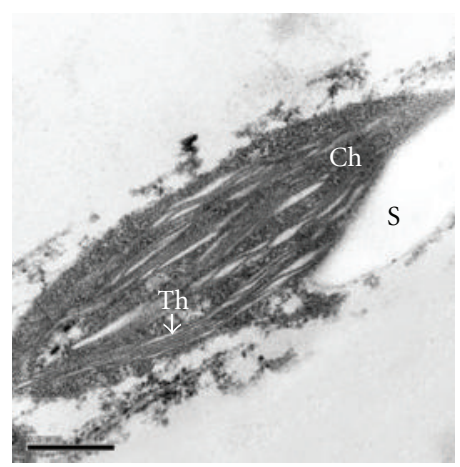

(b)

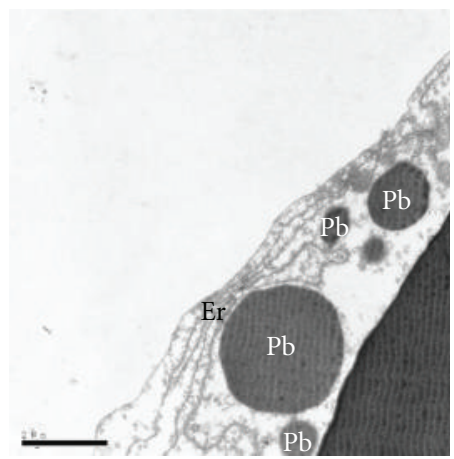

(e)

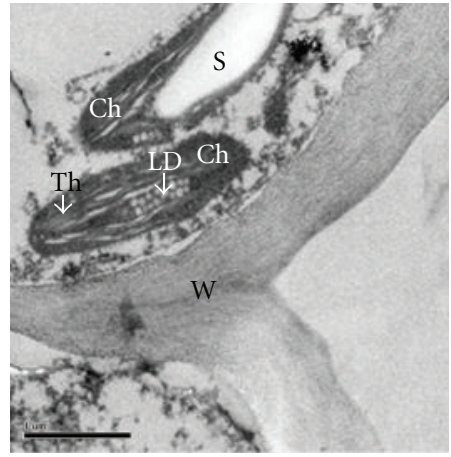

(c)

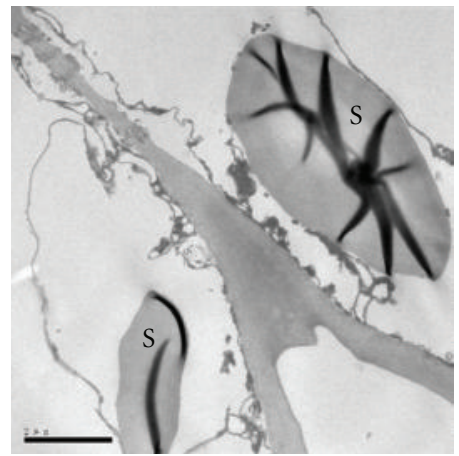

(f)

Figure 3: Ultrastructure of starch granules and protein formation and accumulation in testa cells of G. biloba seeds. (a) Some starch granules accumulated in cells 20 days after pollination; (b) Starch granule accumulated in chloroplast; (c) lipid drops accumulated in chloroplast; (d) many starch granules accumulated in plastid 25 days after pollination (arrows, Er); (e) protein bodies formed by 25 days after pollination; (f) starch granules formed by 30 days after pollination; Er: endoplasmic reticulum; LD: lipid drop; P: protein body; Pl: plastid; Mi: mitochondrion; N: nucleus; S: starch granule; Th: thylakoid; W: wall. ((a), (d), (e), and (f)) bar =2 $\mu \mathrm{m}$; (b) bar = $0.5 \mu \mathrm{m}$; (c) bar $=1 \mu \mathrm{m}$.

growing (Figure 1 (C2)-(C8)). Ultrastructural observations revealed that there were many organelles, including plastids, mitochondria, Golgi, endoplasmic reticulum, and a vacuole in embryo cells (Figures 6(a), 6(b), 6(c), and 6(d)), indicating active metabolism. The plastids were different in shape and size, and some were stretched length-ways and accumulated starch granules in the middle or the ends. The plastids that accumulated starch granules continued developing at each end and shrunk in the middle, becoming dumbbell-shaped before dividing at the constricted point (Figure 6(e), arrows), forming two plastids. By the time of division, some plastids had accumulated starch granules. The plastids that did not accumulate starch granules were also able to proliferate by splitting in the middle (Figures 6(b), 6(c), 6(d), and 6(e)). Some plastids accumulated starch granules that increased in size until they filled the entire plastid (Figure 6(f)), and as starch granules increased in volume, the plastids became amyloids. Usually there were one to four starch granules in each plastid, and each starch granule was irregularly shaped with the long axis less than $2 \mu \mathrm{m}$ (Figure 6(f)). By 20 days after harvest, abundant storage substances had accumulated in the embryo. The C-type starch granules were elliptical, and the long axis was approximately $2-3 \mu \mathrm{m}$ (Figure $6(\mathrm{~g}$ ) and $6(\mathrm{~h}))$. There were many spherical protein bodies of varying sizes, all belonging to the PBI type (Figure 6(i)). These nutrients provide fuel for germination and seedling development.

3.5. Starch Granules in Different Tissues of Seeds. The shape, size, and formation of starch granules were compared in different tissues of Ginkgo seeds as Table 1.

\section{Discussion}

4.1. Formation and Accumulation of Starch Granules in Different Tissues in Seeds. Starch is the major nutrient in the endosperm in seeds, and there have been many studies on the accumulation and structure of starch granules in crop seeds such as wheat and rice. Starch granules have been classified into different groups according to their size; the larger A-type starch granules have a diameter of $10-38 \mu \mathrm{m}$, and the smaller B-type starch granules have a diameter of less than $10 \mu \mathrm{m}$. Both A- and B-type starch granules are spherical or irregular in shape [10-12]. There are also some reports of a C-type starch granule with a diameter of less than $5 \mu \mathrm{m}$ in endosperm tissues [13]. The starch granules in the endosperm tissues of wheat, rice, and angiosperm ovules develop from plastids [14-16]. However, it has also 


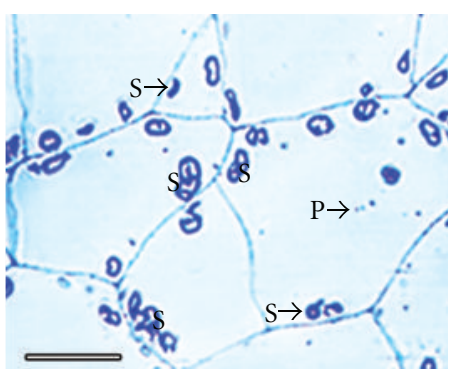

(a)

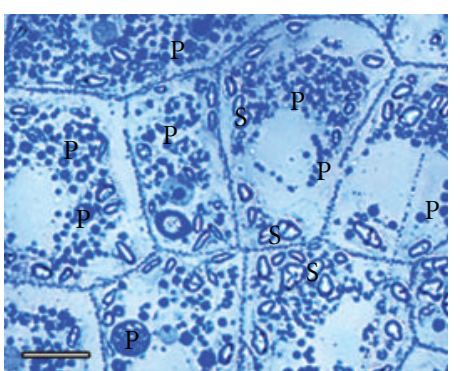

(d)

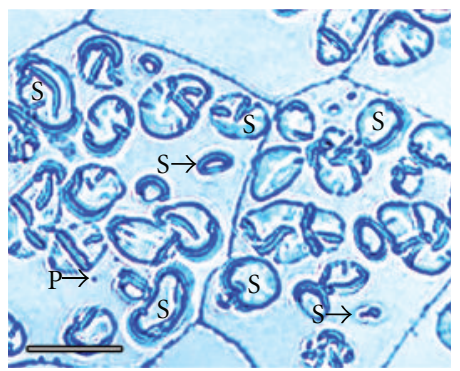

(g)

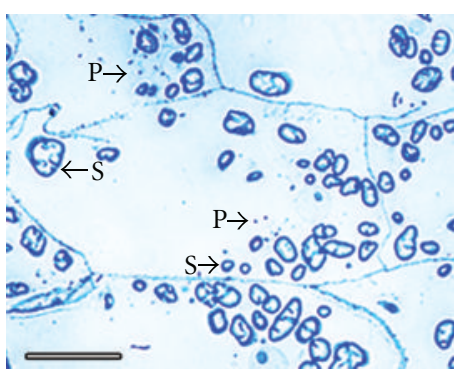

(b)

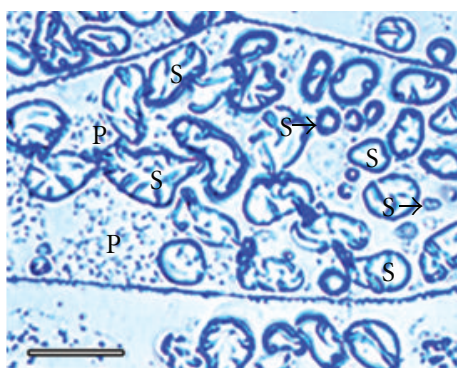

(e)

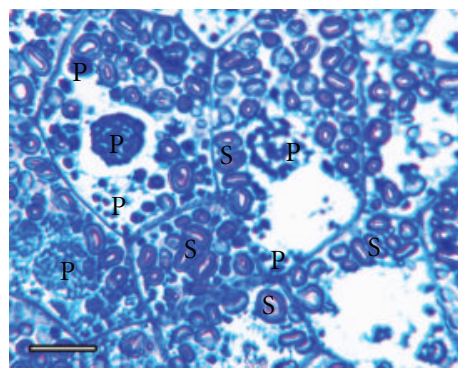

(h)

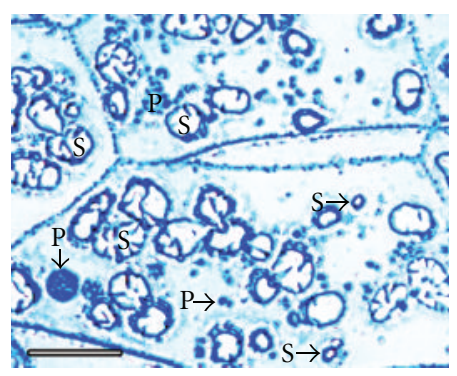

(c)

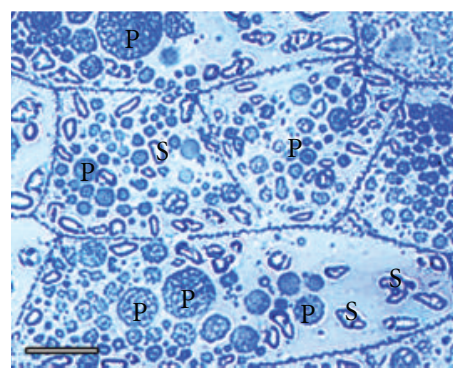

(f)

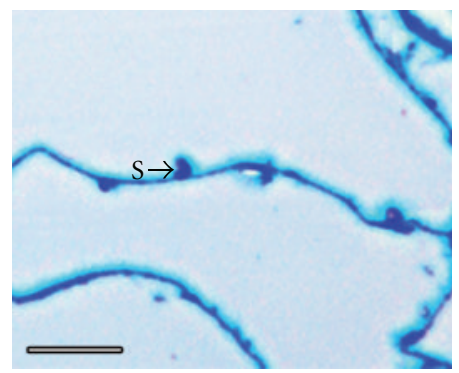

(i)

FIGURE 4: Formation of different types of starch granules and protein accumulation during endosperm development in G. biloba seeds. (a) Endosperm cells 50 days after pollination; (b) endosperm cells 65 days after pollination; (c) endosperm cells 80 days after pollination; (d) outermost cells of endosperm 80 days after pollination; (e) endosperm cells 110 days after pollination; (f) outermost cells of endosperm 110 days after pollination; (g) endosperm cells 155 days after pollination; (f) outermost cells of endosperm 155 days after pollination; (i) endosperm cells near the embryo; P: protein; S: starch granule; N: nucleus. Bar $=20 \mu \mathrm{m}$.

TABLe 1: Shape, size, and formation of starch granules in different tissues of G. biloba seeds.

\begin{tabular}{lccc}
\hline Tissues & Starch granule shape & Starch granule diameter & Location of starch granules \\
\hline \multirow{2}{*}{ Testa } & Round, elliptical, irregular & Type B: $5-6 \mu \mathrm{m}$ & Plastid \\
& & Type C: $2-3 \mu \mathrm{m}$ & Plastid \\
Endosperm & Round, elliptical, irregular & Type B: $5-25 \mu \mathrm{m}$ & Type C: $<5 \mu \mathrm{m}$ \\
& & Type C: $2-3 \mu \mathrm{m}$ & Plastid \\
\hline Embryo & Elliptical, irregular &
\end{tabular}

been proposed that they develop from mitochondria [14]. As starch granules grow, they continuously proliferate by budding, shrinking, and formation of a middle plate and membranous vesicles [17], all of which show that there is active control of this process. There are many factors that influence the accumulation of starch granules in the endosperm, among which is the development of the seed capsule. Research on starch granules in corn endosperm showed that the speed at which the tapetum integument disappeared was closely related to the development of starch granules in endosperm cells. That is, the faster it degraded, the more starch granules accumulated [18]. In wheat, the starch in pericarp cells disappeared as the caryopsis develops [19].

G. biloba produces starchy seeds that contain from 45 to $65 \%$ starch [20]. The starch content is a major factor in seed development and seed quality. Previous research on Ginkgo seeds showed that starch accumulates first in the endosperm [5]. Starch granules can be classified into A-type 


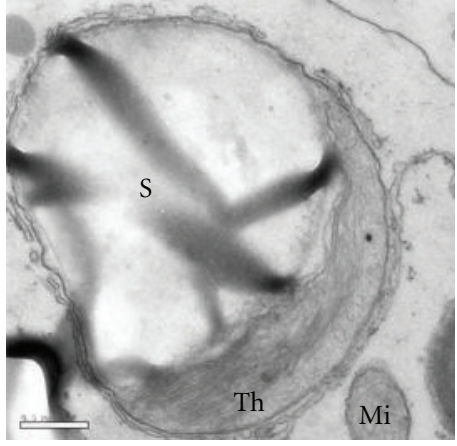

(a)

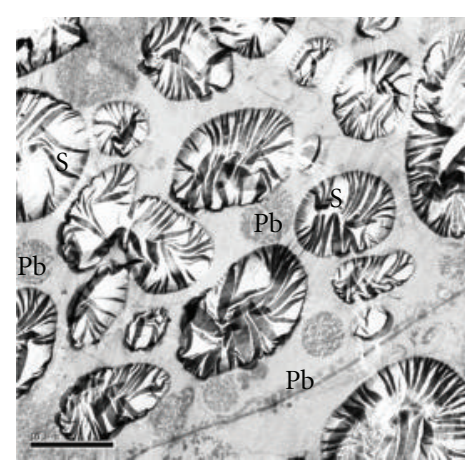

(d)

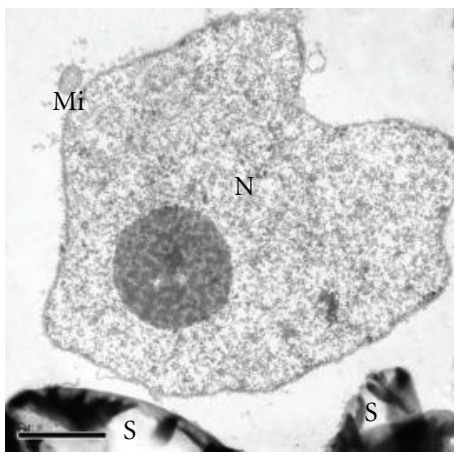

(g)

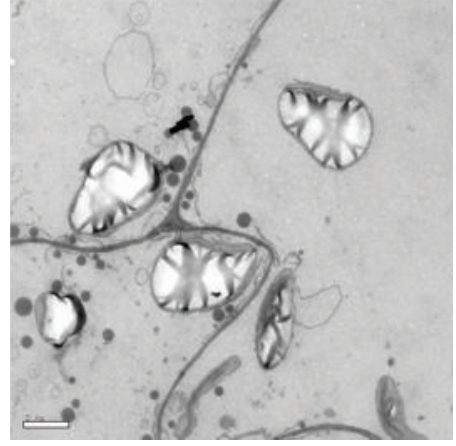

(b)

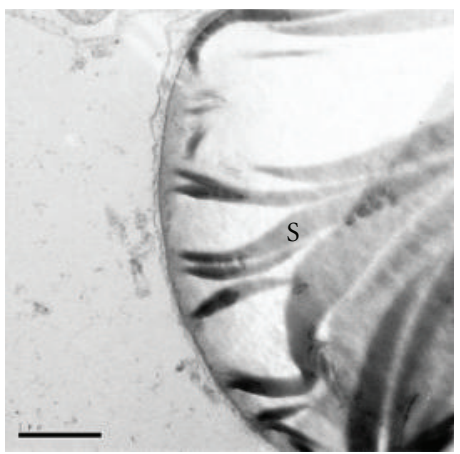

(e)

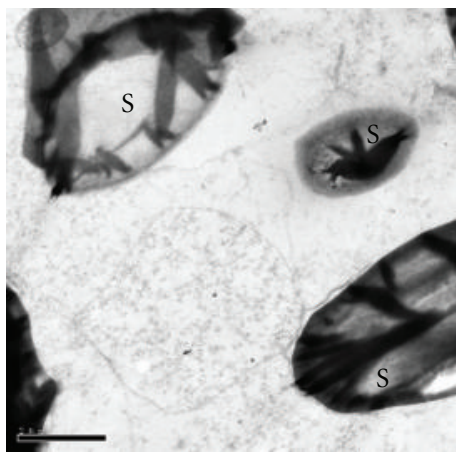

(h)

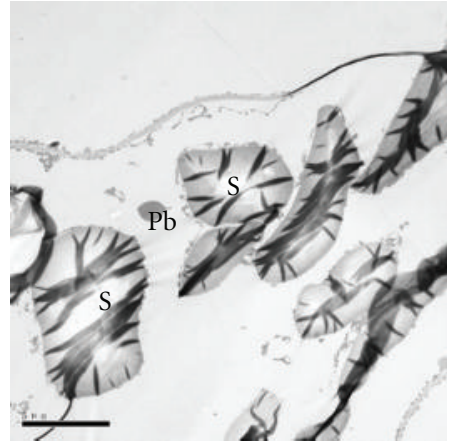

(c)

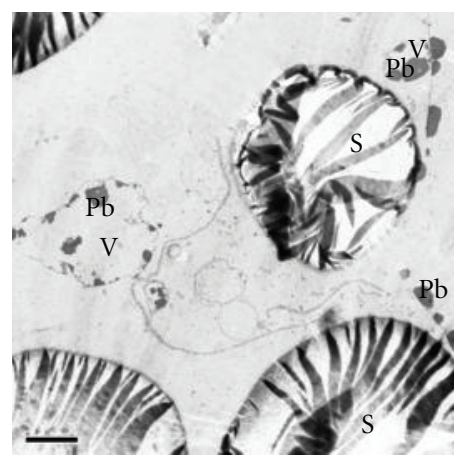

(f)

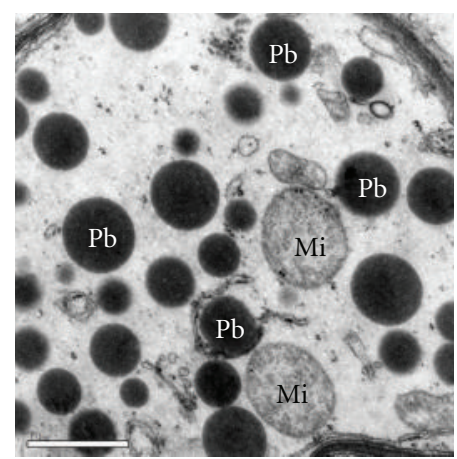

(i)

FIGURE 5: Ultrastructure of starch granules and protein formation and accumulation in endosperm cells of G. biloba seeds. (a) Some starch granules accumulated in chloroplast 50 days after pollination; (b) starch granules accumulated in plastids 50 days after pollination; (c) starch granules increased by 70 days after pollination; ((d), (e)) starch granules 110 days after pollination; (f) protein body; (g) nucleus deformation 130 days after pollination; (h) starch granules 155 days after pollination; (i): protein body; P: protein body; Mi: mitochondrion; N: nucleus; S: starch granule; Th: thylakoid; V: vacuole; W: wall. (a) bar $=0.5 \mu \mathrm{m}$; ((b), (f), (h), and (g)) bar $=2 \mu \mathrm{m}$; (c) bar $=5 \mu \mathrm{m}$; (d) bar $=10 \mu \mathrm{m}$; ((e), (i)) bar $=1 \mu \mathrm{m}$.

or B-type and are spherical or ellipsoidal with a diameter of $5-20 \mu \mathrm{m}[4]$. Whereas there is much information about the formation and accumulation of starch in wheat, rice, and other staple crops, there is little information about the formation and proliferation of starch granules in Ginkgo seeds, especially in different tissues, and the relationship between starch accumulation and seed development. In this study, we observed that the accumulation of starch granules showed different patterns in the various tissues. For example, the testa started accumulating starch granules, but they suddenly disappeared before maturity, while in the endosperm tissues, the starch granules that mainly accumulated in the inner cell layers started to form 50 days after pollination and reached their greatest number and volume by 110 days after pollination. This result suggested that the starch granules in the testa decreased as the endosperm developed, finally disappearing completely. In addition, after the embryo differentiated, many starch granules accumulated as the endosperm developed, the starch granules in the surrounding endosperm tissues decreased and finally disappeared, and 


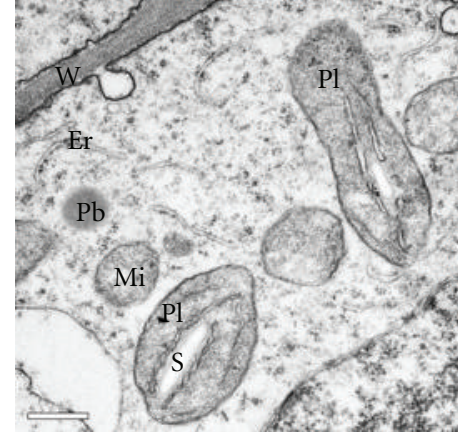

(a)

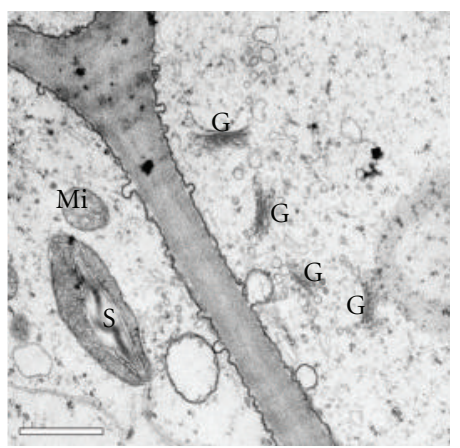

(d)

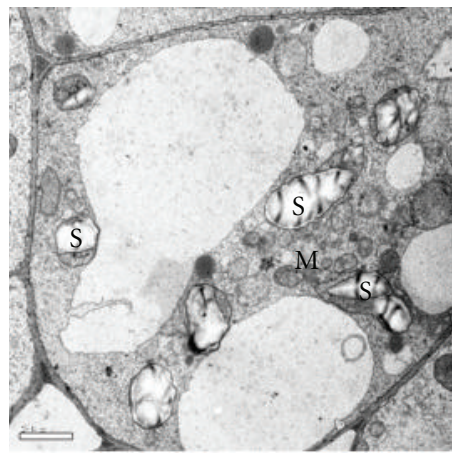

(g)

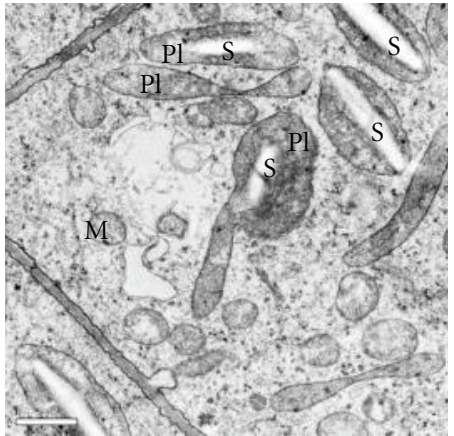

(b)

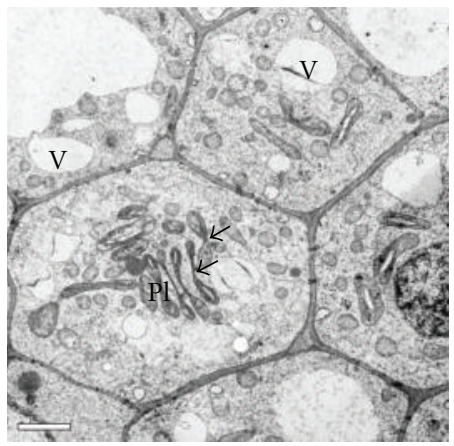

(e)

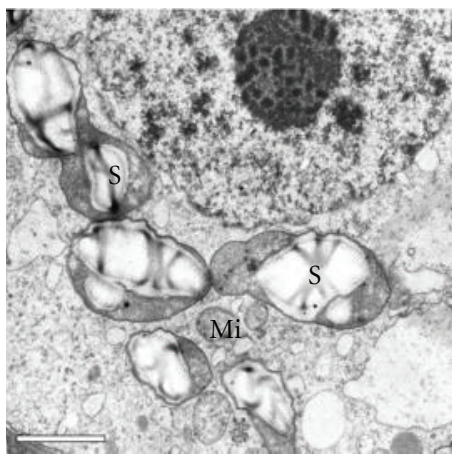

(h)

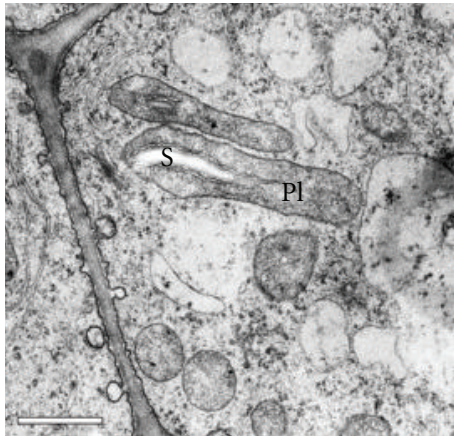

(c)

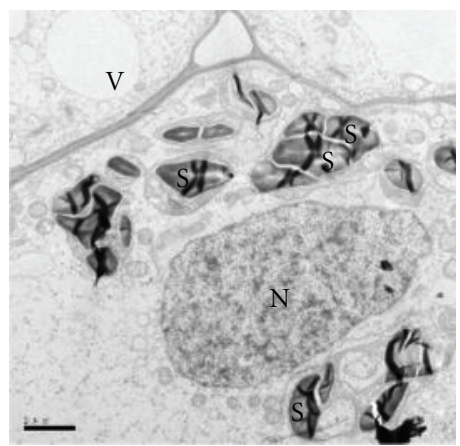

(f)

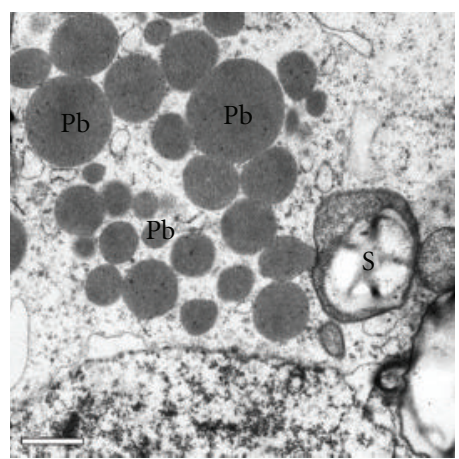

(i)

FIGURE 6: Ultrastructure and accumulation of starch granules and protein bodies in cotyledon cells of G. biloba seeds. ((a)-(d)) Cotyledon 10 days after harvest; ((e), (f)) cotyledon 15 days after harvest; ((g)-(i)) cotyledon 20 days after harvest; Er: endoplasmic reticulum; G: golgi body; Mi: mitochondrion; Pb: protein body; Pl: plastid; S: starch granule; V: vacuole; W: wall. (a) Bar = 0.5 $\mu \mathrm{m}$; ((b), (c), (d), and (i)) bar = $1 \mu \mathrm{m}$; ((e), (f), (h), and (g)) bar $=2 \mu \mathrm{m}$.

the cells degenerated. This suggested that the starch that accumulated in the embryo was mainly derived from the depletion of starch from surrounding endosperm cells.

We compared the formation and accumulation of starch among different tissues in Ginkgo seeds during seed development (Table 1). We found that the starch granules in the testa, endosperm, and embryo accumulated mainly in the plastids and were spherical, ellipsoidal, or irregular in shape. The starch granules proliferated mainly via middle constriction and the formation of a middle plate, similar to the mechanisms observed in seeds of wheat and rice [15-17]. We also observed chloroplasts in both the testa and endosperm during early development, some of which went on to accumulate starch granules and become amyloplasts. This finding was consistent with previous reports that there are fully functional, photosynthetic chloroplasts in the Ginkgo ovule [21]. However, the starch granules from different tissues in Ginkgo seeds differed in size: those in the testa were smaller and were mainly B- and C-types. Those in the endosperm showed wide variations in volume and were mainly A-type, with a few B-type and a small number of C-type. The starch granules in the embryo were mainly Ctype. These findings that $\mathrm{C}$-type starch granules were present in the testa, endosperm, and embryo, and were particularly 
abundant in the testa and embryo cotyledons, differ from the previous conclusion that Ginkgo seeds contain only A- and B-type starch granules [4].

4.2. Formation and Accumulation of Protein Bodies in Different Tissues of Ginkgo Seeds. Protein is another key storage substance in the endosperm of most seeds and is a key nutrient for the embryo. Most proteins exist in the form of protein bodies to supply key proteins and amino acids for seed development [22]. Research on the formation of PBI and PBII indicated that PBI forms directly in the cavity of PB-ER and originates from the ER membranes, while PBII accumulates in the tonoplast in the cytoplasm. The early forming PBI are spherical with a diameter of approximately $1-2 \mu \mathrm{m}$. As their volume increases, the protein bodies lose their spherical shape and fuse together, forming protein bodies that are larger than the largest starch granules. The volume of PBII gradually increases after formation. These protein bodies then enter protein storage vacuoles and group together and connect once inside [23-26]. Once they are formed, the two types of protein bodies are distributed randomly around the starch granules in the endosperm cells [27].

Research on proteins in Ginkgo seeds showed that there are two main types of proteins in the endosperm (watersoluble and salt-soluble) while the embryo of germinating seeds contains mainly alcohol-soluble proteins and glutenins [23]. To date, however, there have been no reports on the formation and accumulation of these proteins in Ginkgo seeds. In the present study, we found that the pattern of accumulation and distribution of protein bodies differed markedly among these tissues. In the testa, protein bodies formed and accumulated 20 days after pollination, but they disappeared as the endosperm developed. The protein bodies in the endosperm accumulated in the outer cell layers by 80 days after pollination, while fewer formed in the inner cell layers. Many protein bodies formed in the embryo as it developed. These contained storage proteins to fuel the later stages of development. Ultrastructure observations revealed two types of protein bodies in Ginkgo seeds, PBI, and PBII. The spherical PBI had ring-like stripes, stained deeply, and were usually surrounded by endoplasmic reticulum. They were scattered in the gaps between starch granules. We can speculate that the PBI proteins in Ginkgo may have formed directly from the endoplasmic reticulum, as is the case in wheat and rice. In addition, in endosperm cells, there was some PBII that was distributed in the vacuoles (Figures $4(\mathrm{~d})$, $4(\mathrm{f})$ and $4(\mathrm{~h}))$. These protein bodies had a large volume and stained a deep black color. The final product, an amorphous protein matrix, was distributed among the starch granules. PBII formed mainly in cells in the outer layers of the endosperm (Figures 4(d), 4(f), and 4(h)), with few in the inner cell layers. These results indicate that during development, many storage proteins form and accumulate in Ginkgo seeds, and among these proteins are endosperm proteins that mainly accumulate in the outer cell layers and show distribution characteristics similar to those of endosperm aleurones in wheat and rice. The large amount of proteins accumulated in the embryo and endosperm will provide nutrients for embryo germination and seedling growth. The formation of PBI- and PBII-type protein bodies and their patterns of accumulation and distribution in endosperm tissues in Ginkgo seeds are similar to those reported for wheat and rice. Such characteristics indicate that though Ginkgo is one of the most ancient gymnosperms the seed development process has many unique features [8], but it also shares some features with other higher plants that have been conserved over the long evolutionary process.

\section{Acknowledgments}

The authors thank Professor Peng Chen and Professor Zhong Wang of Yangzhou University, China, for technical advice. This work was supported by the Natural Science Fund of Jiangsu Province (no. BK2011444), Science and Technology Innovation Fund of Xuzhou City (no. XF11C001), and the National Natural Science Foundation of China (no. 31200145).

\section{References}

[1] Z. Zhou and S. Zheng, "The missing link in Ginkgo evolution," Nature, vol. 423, no. 6942, pp. 821-822, 2003.

[2] L. Wang, Y. P. Wang, Y. Pan, B. Jin, X. Y. Xu, and P. Chen, "Anatomical study of development of ovule in Ginkgo biloba L." Acta Botanica Boreali-Occidentalia Sinica, vol. 27, no. 7, pp. 1349-1356, 2007.

[3] L. Wang, Y. Pan, Y. P. Wang, Q. Wang, X. Y. Xu, and P. Chen, "Observation on amyloplast in endosperm during development of seeds in Ginkgo biloba," Journal of Fruit Science, vol. 24, no. 5, pp. 692-695, 2007.

[4] L. Wang, Q. C. Deng, Y. Zhang, Z. H. Yin, and B. J. Xie, "Morphological and physicochemical properties of Ginkgo starch," Journal of the Chinese Cereals and Oils Association, vol. 22, no. 4, pp. 66-70, 2007.

[5] M. Favre-Duchartre, “Ginkgo, An oviparous plant," Phytomorphology, vol. 8, pp. 377-390, 1958.

[6] L. Wang, B. Jin, M. M. Lin, Y. Lu, N. J. Teng, and P. Chen, "Studies of the development of female reproductive organs in Ginkgo biloba," Chinese Bulletin of Botany, vol. 44, no. 6, pp. 673-681, 2009.

[7] L. Wang, Y. Lu, B. Jin, M. M. Lin, and P. Chen, "Gametophyte development and embryogenesis in Ginkgo biloba: a current view," Chinese Bulletin of Botany, vol. 45, no. 1, pp. 119-127, 2010.

[8] L. Wang, D. Wang, M. M. Lin, Y. Lu, X. X. Jiang, and B. Jin, "An embryological study and systematic significance of the primitive gymnosperm Ginkgo biloba," Journal of Systematics and Evolution, vol. 49, no. 4, pp. 353-361, 2011.

[9] Y. Lu, L. Wang, Y. Pan et al., "Research on starch and protein accumulation and metabolism during the development of the Ginkgo biloba L. female gametophyte," Acta Horticulturae Sinica, vol. 38, no. 1, pp. 15-24, 2011.

[10] S. V. Shinde, J. E. Nelson, and K. C. Huber, "Soft wheat starch pasting behavior in relation to A- and B-type granule content and composition," Cereal Chemistry, vol. 80, no. 1, pp. 91-98, 2003.

[11] H. S. Kim and K. C. Huber, "Channels within soft wheat starch A- and B-type granules," Journal of Cereal Science, vol. 9, pp. 2-14, 2007.

[12] Y. A. Yin, J. C. Qi, W. H. Li, L. P. Cao, and Z. B. Wang, "Physico-Chemical characteristics of A, B type starch granule in 
wheat endosperm," Scientia Agricultura Sinica, vol. 43, no. 11, pp. 2372-2379, 2010.

[13] H. Tang, K. Watanabe, and T. Mitsunaga, "Structure and functionality of large, medium and small granule starches in normal and waxy barley endosperms," Carbohydrate Polymers, vol. 49, no. 2, pp. 217-224, 2002.

[14] R. Li, S. Y. Lan, and X. Z. Xu, "Transformation of mitochondrion to amyloplast and the cytochemical localization of succinic dehydrogenase in rice endosperm," Journal of Chinese Electron Microscopy Society, vol. 21, no. 2, pp. 118-122, 2002.

[15] L. Reale, C. Sgromo, L. Ederli et al., "Morphological and cytological development and starch accumulation in hermaphrodite and staminate flowers of olive (Olea europaea L.)," Sexual Plant Reproduction, vol. 22, no. 3, pp. 109-119, 2009.

[16] J. Tratt, C. J. Prychid, H. D. Behnke, and P. J. Rudall, "Starchaccumulating (S-type) sieve-element plastids in Hydatellaceae: implications for plastid evolution in flowering plants," Protoplasma, vol. 237, no. 1-4, pp. 19-26, 2009.

[17] H. Y. Zhang, "Amyloplast development and proliferation in maize starch endosperm cell," Journal of Maize Sciences, vol. 17, no. 4, pp. 58-60, 2009.

[18] Q. C. Wang, X. Liu, Z. X. Li, and K. C. Liu, "Effect of planting densities on morphogenesis of seed capsule and development of starch granule in maize endosperm," Scientia Agricultura Sinica, vol. 41, no. 8, pp. 2506-2512, 2008.

[19] Z. Wang, Y. J. Gu, W. F. Li, G. Chen, H. Y. Shi, and X. H. Chen, "Development of wheat endosperm and the pathway of nutrient entering the endosperm," Acta Agronomica Sinica, vol. 24, no. 5, pp. 536-545, 1998.

[20] S. Y. Xing, S. M. Li, C. J. Han, F. Zhang, and H. X. Tang, "Comparison on starch characters in endosperm of Ginkgo biloba var. epiphylla Mak. and its systematic significance," Acta Horticulturae Sinica, vol. 37, no. 3, pp. 345-354, 2010.

[21] W. E. Friedman and T. E. Goliber, "Photosynthesis in the female gametophyte of Ginkgo biloba," American Journal of Botany, vol. 73, pp. 1261-1266, 1986.

[22] Q. Q. Liu, L. H. Zhou, H. M. Wang, and M. H. Gu, "Advances on biosynthesis of rice seed storage proteins in molecular biology," Molecular Plant Breeding, vol. 6, no. 1, pp. 1-15, 2008.

[23] H. Liang, B. Xu, W. M. Pan, and W. F. Zhang, "Analysis of proteins in seeds and leaves of Ginkgo biloba L," Journal of Plant Resources and Environment, vol. 9, no. 4, pp. 5-8, 2000.

[24] C. X. Wei, J. Zhang, W. D. Zhou, Y. F. Chen, and R. G. $\mathrm{Xu}$, "Accumulation of storage protein and formation of protein body during wheat endosperm development," Journal of Triticeae Crops, vol. 29, no. 1, pp. 73-78, 2009.

[25] C. X. Wei, J. Zhang, W. D. Zhou, Y. F. Chen, and R. G. $\mathrm{Xu}$, "Accumulation of storage protein and formation of protein body during barley endosperm development," Acta Agronomica Sinica, vol. 35, no. 2, pp. 334-340, 2009.

[26] Y. Saito, T. Shigemitsu, K. Tanaka, S. Morita, S. Satoh, and T. Masumura, "Ultrastructure of mature protein body in the starchy endosperm of dry cereal grain," Bioscience, Biotechnology and Biochemistry, vol. 74, no. 7, pp. 1485-1487, 2010.

[27] R. M. Zhou, Y. T. Zhang, A. M. Li et al., "Effect of booting nitrogen on accumulation of grain protein components and development of protein body in wheat," Journal of Triticeae Crops, vol. 29, no. 6, pp. 1022-1026, 2009. 

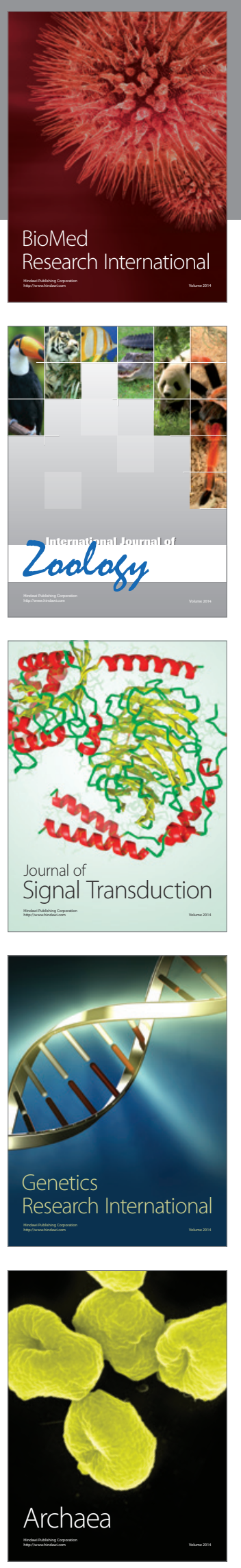
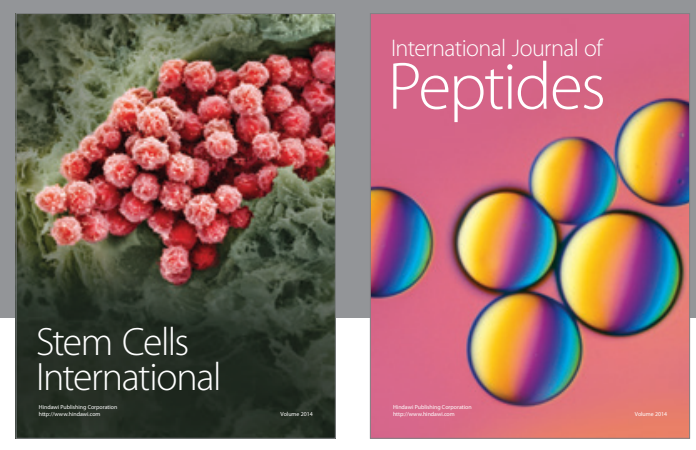

Submit your manuscripts at

http://www.hindawi.com
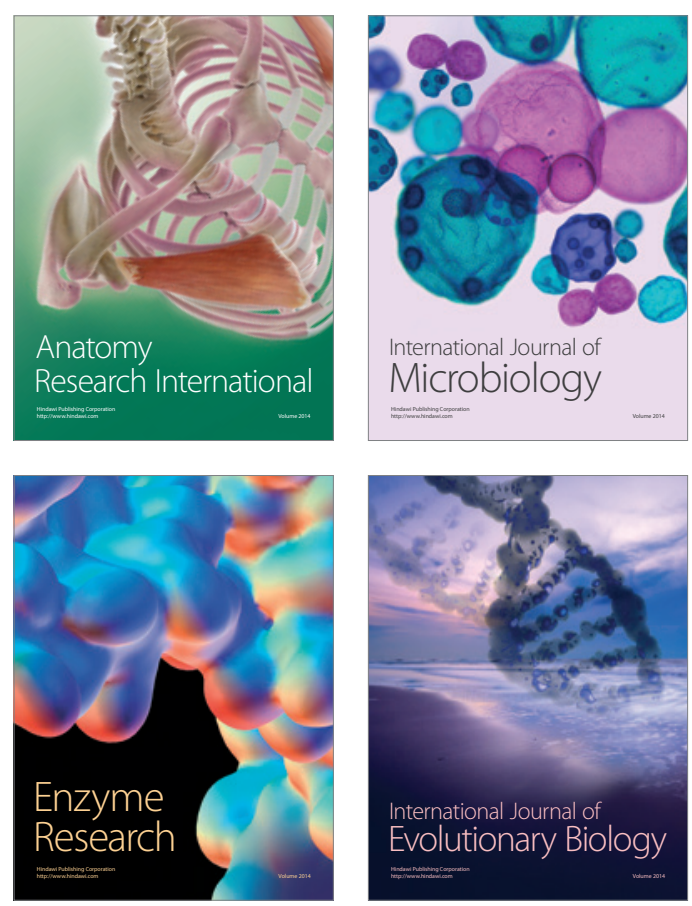
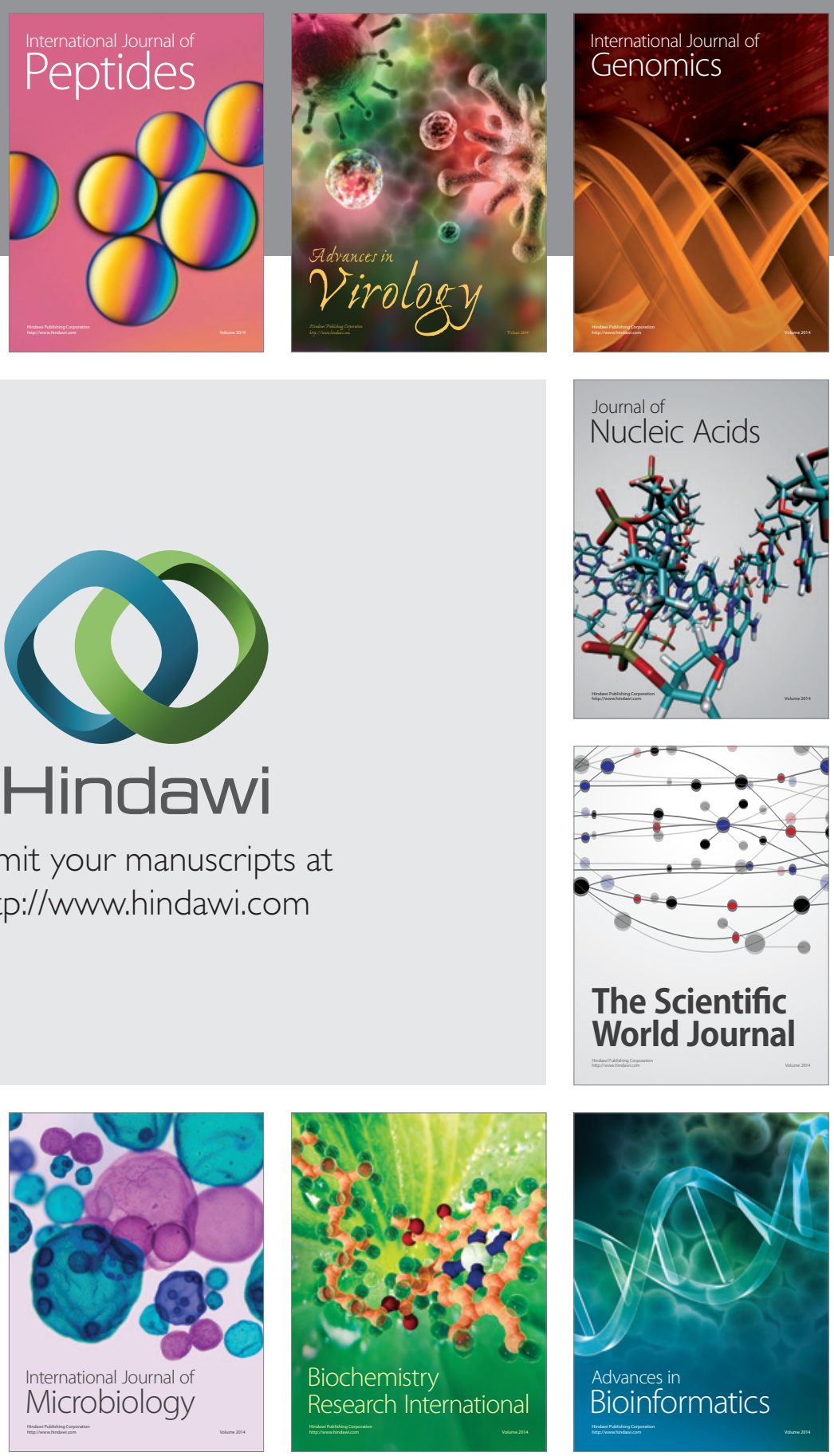

The Scientific World Journal
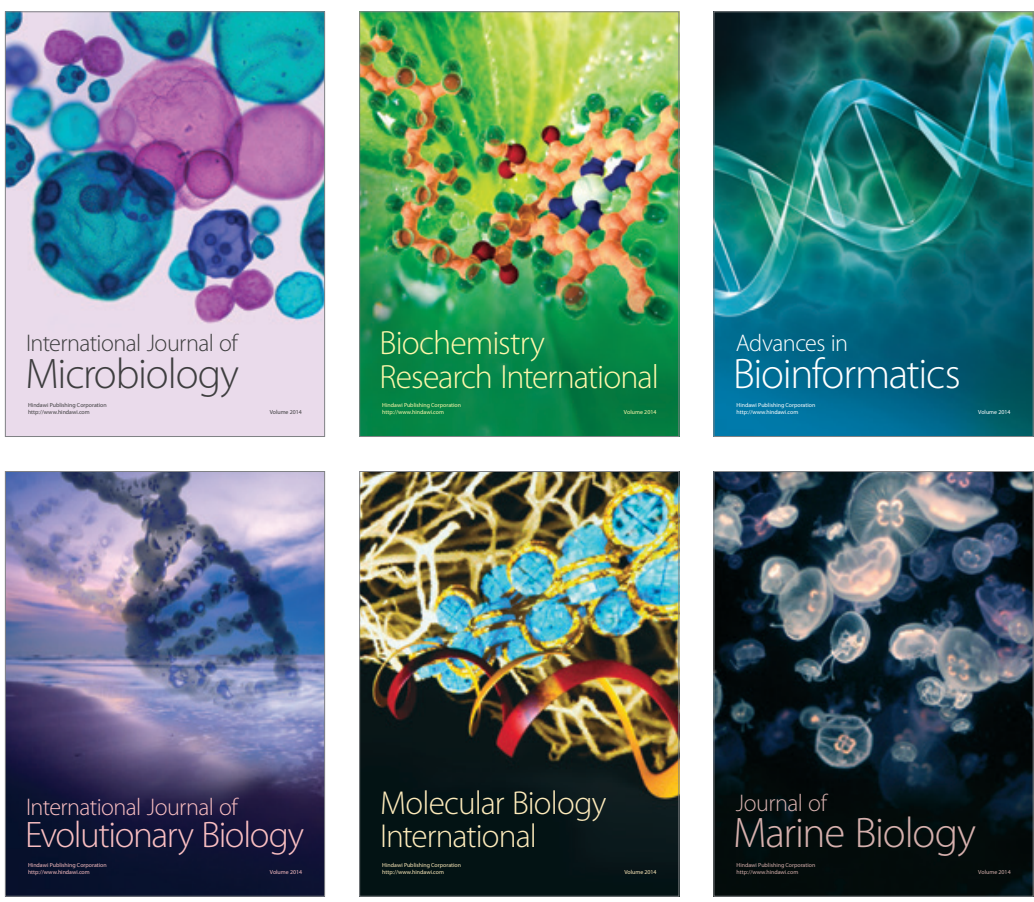